\title{
Scavenging of black carbon in mixed phase clouds at the high alpine site Jungfraujoch
}

\author{
J. Cozic ${ }^{1}$, B. Verheggen ${ }^{1, *}$, S. Mertes ${ }^{2}$, P. Connolly ${ }^{3}$, K. Bower ${ }^{3}$, A. Petzold ${ }^{4}$, U. Baltensperger ${ }^{1}$, and E. Weingartner ${ }^{1}$ \\ ${ }^{1}$ Laboratory of Atmospheric Chemistry, Paul Scherrer Institut, 5232 Villigen PSI, Switzerland \\ ${ }^{2}$ Leibniz-Institute for Tropospheric Research, 04318 Leipzig, Germany \\ ${ }^{3}$ School of Earth, Atmospheric and Environmental Sciences, University of Manchester, M60 1QD, UK \\ ${ }^{4}$ Institute for Atmospheric Physics, German Aerospace Centre, 82234 Wessling, Germany \\ *now at: the Institute of Atmospheric and Climate Sciences, ETH Zürich, 8092, Switzerland
}

Received: 23 October 2006 - Published in Atmos. Chem. Phys. Discuss.: 23 November 2006

Revised: 22 March 2007 - Accepted: 23 March 2007 - Published: 11 April 2007

\begin{abstract}
The scavenging of black carbon (BC) in liquid and mixed phase clouds was investigated during intensive experiments in winter 2004, summer 2004 and winter 2005 at the high alpine research station Jungfraujoch ( $3580 \mathrm{~m}$ a.s.l., Switzerland). Aerosol residuals were sampled behind two well characterized inlets; a total inlet which collected cloud particles (droplets and ice particles) as well as interstitial (unactivated) aerosol particles; an interstitial inlet which collected only interstitial aerosol particles. BC concentrations were measured behind each of these inlets along with the submicrometer aerosol number size distribution, from which a volume concentration was derived. These measurements were complemented by in-situ measurements of cloud microphysical parameters. $\mathrm{BC}$ was found to be scavenged into the condensed phase to the same extent as the bulk aerosol, which suggests that $\mathrm{BC}$ was covered with soluble material through aging processes, rendering it more hygroscopic. The scavenged fraction of $\mathrm{BC}\left(F_{\mathrm{Scav}, \mathrm{BC}}\right)$, defined as the fraction of $\mathrm{BC}$ that is incorporated into cloud droplets and ice crystals, decreases with increasing cloud ice mass fraction (IMF) from $F_{\text {Scav, BC }}=60 \%$ in liquid phase clouds to $\mathrm{F}_{\mathrm{Scav}, \mathrm{BC}} \sim 5-$ $10 \%$ in mixed-phase clouds with $\mathrm{IMF}>0.2$. This can be explained by the evaporation of liquid droplets in the presence of ice crystals (Wegener-Bergeron-Findeisen process), releasing $\mathrm{BC}$ containing cloud condensation nuclei back into the interstitial phase. In liquid clouds, the scavenged BC fraction is found to decrease with decreasing cloud liquid water content. The scavenged $\mathrm{BC}$ fraction is also found to decrease with increasing $\mathrm{BC}$ mass concentration since there is an increased competition for the available water vapour.
\end{abstract}

Correspondence to: E. Weingartner

(ernest.weingartner@psi.ch)

\section{Introduction}

Atmospheric aerosol particles may play a major role in climate change by absorbing and scattering solar and infrared radiation, referred to as the direct forcing and discussed in detail by e.g. Haywood and Boucher (2000). Aerosol particles can also indirectly influence climate by altering the microphysical properties of clouds, e.g. as reviewed by Lohmann and Feichter (2005). This indirect forcing is caused by the ability of aerosol particles to act as cloud condensation nuclei (CCN) or ice nuclei (IN). With increasing $\mathrm{CCN}$ number concentration, caused by e.g. human activity, more and smaller droplets are formed in warm clouds (Twomey effect). As a consequence, and under the assumption that the cloud liquid water content (LWC) stays constant, the cloud albedo and thus the reflection of solar radiation increase (Twomey, 1977). In addition, the reduction of cloud droplet size weakens precipitation development, resulting in more persistent clouds (cloud lifetime effect) (Albrecht, 1989). Although little is known about the response of warm clouds to a changing aerosol population, even less is known about the effects on and feedback mechanisms associated with glaciated or mixed-phase clouds (Lohmann and Feichter, 2005). The presence of ice crystals is important for climate, because they influence the cloud radiative properties and they lead to precipitation (Rogers and Yau, 1989; Lau and $\mathrm{Wu}, 2003)$. The aerosol indirect forcing has been estimated to have the highest uncertainty in assessing human impact on climate change (IPCC, 2001).

The atmospheric aerosol mainly consists of non-light absorbing components such as sulphates, nitrates, and organics, which scatter solar radiation and thus lead to a cooling of the climate system. Aerosol particles can also contain light

Published by Copernicus GmbH on behalf of the European Geosciences Union. 
absorbing material such as black carbon (BC), which exerts a positive forcing at the top of the atmosphere. This might partly offset the cooling due to the scattering (IPCC, 2001). This positive forcing can be amplified if absorption of solar radiation by $\mathrm{BC}$ occurs within cloud droplets or for a coated BC particle (Chylek et al., 1996). When absorption occurs in a cloud droplet, the resulting increase in temperature reduces the relative humidity and may result in the evaporation of cloud droplets (semi-indirect effect) (Lohmann and Feichter, 2005, and cited references therein). The reduced cloud cover and cloud optical depth will in turn further amplify warming of the Earth-atmosphere system.

Freshly emitted soot particles are mostly hydrophobic, i.e. they barely act as CCN (Weingartner et al., 1997). Due to atmospheric aging processes, BC is often coated with secondary aerosol material (such as inorganic ions) at remote locations in the atmosphere. This aged BC exhibits a larger hygroscopicity and the transfer of $\mathrm{BC}$ into cloud droplets via nucleation scavenging is therefore enhanced. In-cloud scavenging of $\mathrm{BC}$ contributes to its removal from the atmosphere and thereby affects its lifetime. It is also important for the positive radiative forcing of $\mathrm{BC}$ which strongly influences the uncertainties of the net cloud radiative forcing. The ability of BC to act as IN is also important to consider since it is an anthropogenic compound which may cause a glaciation indirect forcing, whereby the increased formation of ice crystals enhances precipitation, thus causing a decrease in cloud lifetime and cloud cover (Lohmann, 2002; Lohmann and Diehl, 2006). This forcing may work in the opposite direction compared to the indirect forcing of aerosols acting as $\mathrm{CCN}$ in liquid clouds or mixed phase clouds and thus results in a warming of the atmosphere. During our campaigns, BC content of ice residuals was also measured. The ability of $\mathrm{BC}$ to act as IN will be discussed in a separate paper (Cozic et al., 2007a $\mathrm{a}^{1}$.

The scavenged fraction of BC $\left(F_{\text {Scav }, \mathrm{BC}}\right)$ is defined as the fraction of $\mathrm{BC}$ that is incorporated into cloud droplets and ice crystals. Previous studies have shown that the scavenged BC fraction increases with increasing distance from source regions, from 0.06 in heavily polluted Po Valley fog (Hallberg et al., 1992) to 0.8 in a remote area in Spitzbergen (Heintzenberg and Leck, 1994). Table 1 lists scavenged BC fractions from the literature. Some of these studies (Hitzenberger et al., 2000; Kasper-Giebl et al., 2000) calculated the scavenged fraction from the comparison between cloud impactor samples and interstitial aerosols and not as in our study with total and interstitial concentrations.

From Table 1, it is obvious that the atmospheric aging processes which transform hydrophobic, freshly emitted soot particles into hygroscopic internally mixed aerosol

\footnotetext{
${ }^{1}$ Cozic, J., Verheggen, B., Mertes, S., Connolly, P., Gallagher, M., Baltensperger, U., and Weingartner, E.: Enrichment of black carbon in ice residuals suggests a potential ice nucleating capability, in preparation, 2007a.
}

are important factors to increase the scavenged $\mathrm{BC}$ fraction. Nevertheless, the slightly different results observed at Mt Sonnblick during two different studies in the same season indicate that other parameters besides the atmospheric processing of the air mass affect the scavenged $\mathrm{BC}$ fraction as well. Hitzenberger et al. $(2000,2001)$ and Kasper-Giebl et al. (2000) found that the scavenged BC fraction increases with increasing LWC. Sellegri et al. (2003) did not find such a dependence on LWC. Hallberg et al. $(1992,1994)$ and Gieray et al. (1997) found that the scavenged BC fraction decreases with increasing total $\mathrm{BC}$ concentration. Other studies (Hitzenberger et al., 2000, 2001; Kasper-Giebl et al., 2000) did not find such a dependence on the $\mathrm{BC}$ concentration.

The purpose of this study is to further increase the knowledge of the processes which determine the partitioning of $\mathrm{BC}$ between the interstitial particle phase (i.e. not activated particles) and the condensed phase (i.e. cloud droplets and ice crystals). The new aspect in this paper compared to the others is that measurements were carried out in liquid and mixedphase clouds. This allowed the assessment of temperature and ice mass fraction as an additional significant factor in determining the scavenged fraction. The different sampling systems, the instrumentation and the site are first described. Then the impacts of some environmental parameters (LWC, total $\mathrm{BC}$ concentration, temperature, ice mass fraction) on the scavenged fraction of $\mathrm{BC}$ are discussed.

\section{Site, sampling and analysis}

Measurements were conducted during several Cloud and Aerosol Characterization Experiments (CLACE) at the high-alpine research station Jungfraujoch (Switzerland, $3580 \mathrm{~m}$ a.s.1.). Sampling was performed in March 2004 (CLACE 3), from mid July to the end of September 2004 (CLACE 3.5) and from mid February to mid March 2005 (CLACE 4). More than $3500 \mathrm{~h}$ of data were collected and analyzed, with approximately $1000 \mathrm{~h}$ of "in-cloud" measurements (37\% average cloud coverage in winter and $20 \%$ in summer). A wide variety of physical and chemical parameters were measured downstream of three well characterized inlets and complemented by in-situ measurements of cloud microphysical parameters (see below).

Previous studies used simultaneously measured submicrometer number size distributions (total and interstitial) in order to calculate the aerosol scavenged number fraction $\left(F_{\mathrm{Scav}, \mathrm{N}}\right)$ at the Jungfraujoch (Henning et al., 2002, 2004). The scavenged number fraction $\left(F_{\mathrm{Scav}, \mathrm{N}}\right)$ is defined as the fraction of the total number of particles (particle diameter $D>100 \mathrm{~nm}$ ) that are incorporated into cloud droplets and ice crystals. They also found a clear dependency of $F_{\text {Scav,N }}$ on temperature. These findings have been complemented with the analysis of the $F_{\text {Scav,N }}$ dependency on cloud 
Table 1. Average scavenged BC fractions from the literature.

\begin{tabular}{|c|c|c|c|c|}
\hline Sampling site & $F_{\text {Scav }, \mathrm{BC}}$ & Type of site & Papers & Date \\
\hline $\begin{array}{l}\text { Po Valley } \\
\text { (Italy) }{ }^{\circ}\end{array}$ & 0.06 & Urban & Hallberg et al. (1992) & November 1989 \\
\hline $\begin{array}{l}\text { Kleiner Feldberg } \\
{\text { (Germany })^{\circ}}^{{ }^{\circ}}\end{array}$ & 0.15 & Rural & Hallberg et al. (1994) & October-November 1990 \\
\hline $\begin{array}{l}\text { Puy de Dôme } \\
\text { (France) }\end{array}$ & 0.33 & $\begin{array}{l}\text { Mid altitude } \\
(1465 \mathrm{~m})\end{array}$ & Sellegri et al. (2003) & Feb-April 2001 \\
\hline $\begin{array}{l}\text { Mt. Sonnblick } \\
\text { (Austria) }^{\circ}\end{array}$ & 0.45 & $\begin{array}{l}\text { High } \\
(3106 \mathrm{~m})\end{array}$ & Kasper-Giebl et al. (2000) & September 1995 \\
\hline $\begin{array}{l}\operatorname{Rax} \\
\text { (Austria) }^{\circ}\end{array}$ & 0.54 & $\begin{array}{l}\text { Mid altitude } \\
(1644 \mathrm{~m})\end{array}$ & Hitzenberger et al. (2001) & March 2000-April 1999 \\
\hline $\begin{array}{l}\text { Great Dun Fell } \\
\text { (UK) }\end{array}$ & 0.57 & Rural - Coastal & Gieray et al. (1997) & April-May 1993 \\
\hline $\begin{array}{l}\text { Jungfraujoch } \\
\text { (Switzerland) * }\end{array}$ & 0.61 & $\begin{array}{ll}\text { High } & \text { altitude } \\
(3850 \mathrm{~m}) & \end{array}$ & This work & July-August 2004 \\
\hline $\begin{array}{l}\text { Mt. Sonnblick } \\
\text { (Austria) }^{\circ}\end{array}$ & 0.74 & $\begin{array}{l}\text { High } \\
(3106 \mathrm{~m})\end{array}$ & Hitzenberger et al. (2000) & September 1996 and April-May 1997 \\
\hline $\begin{array}{l}\text { Spitzbergen } \\
\text { (Norway) }\end{array}$ & 0.80 & Artic & Heintzenberg and Leck (1994) & Winter and summer (1990-1992) \\
\hline
\end{tabular}

*summer liquid cloud only ${ }^{\circ}$ scavenged fraction calculated with cloud liquid impactor

microphysical parameters which results are presented in a series of papers (Mertes et al., 2007²; Verheggen et al., 2007³).

\subsection{The Jungfraujoch station}

The Jungfraujoch measurement site is located on an exposed mountain col in the Swiss Alps at $3580 \mathrm{~m}$ a.s.l. It is a Global Atmosphere Watch (GAW) station where atmospheric aerosols and gases have been measured for more than a decade. The station is regularly engulfed in clouds $(30 \%$ of the time averaged over the three campaigns discussed in this study). Due to its location and altitude, the site is far away from significant pollution sources (only occasionally local construction work causes measurable emissions). These characteristics make the Jungfraujoch well suited to investigate continental background aerosols and clouds from a ground based platform.

All aerosol parameters measured over an extended period at the Jungfraujoch exhibit a strong seasonal cycle with a maximum in summer and a minimum in winter. This is due

\footnotetext{
${ }^{2}$ Mertes, S., Verheggen, B., Walter, S., Ebert, M., Connolly, P., Weingartner, E., Schneider, J., Bower, K. N., Inerle-Hof, M., Cozic, J., Baltensperger, U., and Heintzenberg, J.: Counterflow virtual impactor based collection of small ice particles in mixed-phase clouds for the physico-chemical characterisation of tropospheric ice nuclei: sampler description and first case study, Environ. Sci. Technol., submitted, 2007.

${ }^{3}$ Verheggen, B., Cozic, J., Weingartner, E., Bower, K., Mertes, S., Connolly, P., Flynn, M., Gallagher, M., Choularton, T., and Baltensperger, U.: Aerosol activation in mixed phase clouds at the high Alpine site Jungfraujoch, J. Geophys. Res., submitted, 2007.
}

to the fact that in summer the site is influenced by injections of air from the more polluted planetary boundary layer caused by thermal convection during afternoons with high solar insulation. In wintertime these processes are much less frequent resulting in substantially lower aerosol concentrations (Weingartner et al., 1999; Henne et al., 2005). Therefore, the site is deemed representative of the lower free troposphere above a continental area. More information on the Jungfraujoch site and the long-term aerosol measurements are found in Baltensperger et al. (1997) and Collaud Coen et al. (2007).

\subsection{Inlets}

The partitioning of aerosol particles in mixed-phase clouds was investigated by sampling air through three well characterized inlets. A heated $\left(25^{\circ} \mathrm{C}\right)$, total aerosol inlet was used to evaporate cloud droplets and ice crystals at an early stage of the sampling process. This inlet was designed to sample cloud droplets smaller than $40 \mu \mathrm{m}$ at wind speeds of up to $20 \mathrm{~m} / \mathrm{s}$ (Weingartner et al., 1999). The total inlet sample thus consists of interstitial (unactivated) particles as well as of the residues of cloud droplets and ice crystals. This inlet is also used for the continuous GAW measurements.

The second inlet was designed to sample only interstitial aerosol by removing cloud particles from the sampled air, using an aerodynamic size discriminator $\left(\mathrm{PM}_{2.5}\right.$, Very Sharp Cut Cyclone, BGI, USA) operating at a high flow rate $(\sim 20 \mathrm{lpm})$ resulting in a cutoff of $D_{50}=2 \mu \mathrm{m}$ at ambient temperature $\left(T \approx-10^{\circ} \mathrm{C}\right)$. During cloud presence, the difference in a particular instrument response between the total and 
interstitial inlets enables the determination of the partitioning of the particles present only in the cloud phase. The inlet was cleaned regularly to avoid riming and clogging by snow.

The third inlet is the so-called "Ice Counterflow Virtual impactor" (Ice-CVI), which was designed to sample residual particles of small ice crystals and/or cloud droplets (Mertes et al., 20072). The ability of BC to act as IN will be discussed in a separate paper (Cozic et al., 2007a $\mathrm{a}^{1}$ ).

\subsection{Black carbon measurements}

Two Multi-Angle Absorption Photometers (MAAP, Thermo ESM Andersen) operating at a nominal wavelength of $\lambda=630 \mathrm{~nm}$ (Petzold and Schönlinner, 2004) were used to measure the particle light absorption coefficient from which the $\mathrm{BC}$ mass concentration was derived. As determined during a recent intercomparison study at the IfT in Leipzig, Germany in November 2005, the correct wavelength of the employed light source in the MAAP is $635 \mathrm{~nm}$ (Thomas Müller, personal communication). One instrument was connected to the total inlet and the second was installed downstream of the interstitial inlet. The time resolution was set to $1 \mathrm{~min}$ and the data were averaged to a common time base of $10 \mathrm{~min}$.

The principle of the MAAP is to measure continuously and simultaneously the transmission and the back scattering of a light beam with a defined wavelength through a fiber filter, through which the aerosol is sampled. The light absorption coefficient, $b_{\mathrm{abs}}$, is obtained from a radiative transfer scheme which corrects for artifacts caused by the interaction of the light with the filter material (Petzold and Schönlinner, 2004).

Black carbon is the most efficient light-absorbing aerosol species in the visible spectral range. The relationship between the aerosol absorption coefficient, $b_{\mathrm{abs}}\left(\mathrm{m}^{-1}\right)$, and the corresponding black carbon mass concentration, $\mathrm{BC}\left(\mathrm{gm}^{-3}\right)$, is established by the mass absorption efficiency, $\sigma_{\mathrm{abs}, \mathrm{BC}}$ $\left(\mathrm{m}^{2} \mathrm{~g}^{-1}\right)$, via the relationship

$b_{\mathrm{abs}}=\mathrm{BC} \cdot \sigma_{\mathrm{abs}, \mathrm{BC}}$

where $\sigma_{\mathrm{abs}, \mathrm{BC}}$ and $b_{\mathrm{abs}}$ are wavelength dependent.

A thermo-optical method (OC/EC analyzer, Sunset laboratory Inc.) was used to determine the mass absorption efficiency $\left(\sigma_{\mathrm{abs}}\right)$, assuming that elemental carbon (EC) is equivalent to BC. For the MAAP a $\sigma_{\text {abs }}$ of $7.6 \mathrm{~m}^{2} \mathrm{~g}^{-1}$ was obtained in winter and $11 \mathrm{~m}^{2} \mathrm{~g}^{-1}$ in summer at $635 \mathrm{~nm}$ (details can be found in Cozic et al., 2007b ${ }^{4}$ ).

Another light absorbing aerosol component is hematite $\left(\mathrm{Fe}_{2} \mathrm{O}_{3}\right)$, a minor component of mineral dust, which usually makes a small contribution but can be important during Saharan dust events (Collaud Coen et al., 2004). Because of the relatively low mass absorption efficiency of mineral dust $\left(\sigma_{\text {abs }}(660 \mathrm{~nm}) \sim 0.02-0.01 \mathrm{~m}^{2} \mathrm{~g}^{-1}\right.$ (Alfaro et al.,

\footnotetext{
${ }^{4}$ Cozic, J., Verheggen, B., Steinbacher, M., Hüglin, C., Bower, K., Crosier, J., Baltensperger, U., and Weingartner, E.: Mass closure of free Tropospheric aerosol for TSP and PM1 at the high alpine site Jungfraujoch, in preparation, 2007b.
}

2004; Linke et al., 2006)), the overall contribution of this component to the absorption coefficient is expected to be small during periods that are not influenced by Saharan dust events. Such Saharan dust episodes occur at the Jungfraujoch site on average 24 times a year (ranging from 10 to 34 per year in the last 5 years) with different duration (Collaud Coen et al., 2004). They were excluded from the following analysis by considering the wavelength dependence of the single scattering albedo as discussed by Collaud Coen et al. (2004). Another component suspected to be able to contribute to the measured absorption coefficient is light absorbing organic material. Again the low mass absorption efficiency associated with organic compounds (e.g. for HULIS $\sigma_{\text {abs }}(532 \mathrm{~nm}) \sim 0.03 \mathrm{~m}^{2} \mathrm{~g}^{-1}$ (Hoffer et al., 2006)) would require unrealistically high concentrations of these compounds to significantly contribute to the measured absorption coefficient. We therefore assume that outside Saharan dust episodes, the measured absorption coefficient is entirely due to absorption by $\mathrm{BC}$.

\subsection{Particle size distribution measurements}

Two Scanning Mobility Particle Sizers (SMPS, TSI 3934), consisting of a DMA (TSI 3071) and CPC (TSI 3022), were used to measure the particle size distribution between 17 and $900 \mathrm{~nm}$ (dry) diameter, which are discussed by Verheggen et al. $(2007)^{3}$. One SMPS was automatically switched every 6 min between the total (TOT) and interstitial inlets (INT), whereas another one was dedicated to the ICE-CVI inlet (winter 2004 and 2005 only).

During cloud-free conditions the response of the TOT and INT inlets should be identical. The INT spectrum was corrected towards the TOT spectrum by a size dependent correction factor for the small systematic difference between the two (INT was always $\leq 5 \%$ lower than TOT), as particle losses were expected to be higher in the INT, due to a longer residence time in the sampling line. In addition, the flow rate in the INT was biased to slightly higher values $(<2 \%)$, due to a slight under-pressure caused by the cyclone.

\subsection{Cloud microphysical measurements}

Cloud particles in the size range 10 to $2300 \mu \mathrm{m}$ were imaged with a Cloud Particle Imager (CPI, SPEC Inc. 230X) (winter campaigns only). The CPI records images of individual cloud particles that pass through its sample volume. In general, the images are oversized from their true size as they are a finite distance away from the object plane of the imaging optics. This means that the standard processing of the CPI data yields only qualitative size distributions. For our dataset, a semi-empirical calibration (described by Connolly, 2006, and Connolly et al., 2007) was used to correct the particle size and accurately define the probe sample volume. This method enables quantitative measurements of cloud particle size distributions to be made with the CPI. The particle size 


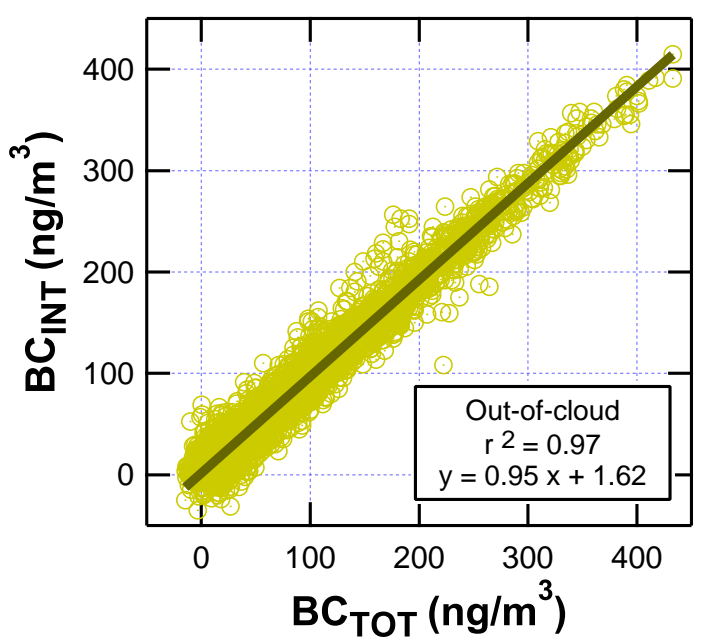

Fig. 1. Comparison of the BC concentrations (determined by two MAAPs) from the total and interstitial inlet during clear sky conditions $\left(\mathrm{CWC}<0.01 \mathrm{~g} / \mathrm{m}^{3}\right)$ for $1800 \mathrm{~h}$ of measurements. Symbols represent 10-min averages.

distribution and mass concentration from the CPI was validated using a PMS 2-D grey scale particle imaging spectrometer (Modified PMS Model OAP-2DG-64). Another aspect that has been assumed to potentially affect microphysical aircraft probe data is the shattering of large ice crystals as they impact on the probe inlet. Since our measurements were made from a ground-based platform, droplet and/or crystal shattering due to high wind speeds (as aircraft measurements are subjected to) was minimal. Nevertheless, periods when shattering might have occurred, as evident from the measured images, were removed from further analysis.

The volume of each imaged particle, necessary to compute the ice water content (IWC), was inferred from the 2dimensional CPI images based on the empirical size-mass relationships given by Heymsfield et al. (2004) and Mitchell (1996). Spherical particles were assumed to be predominantly liquid and were thus excluded from the IWC. A comparison of the CPI derived IWC with the condensed water content measured downstream of the Ice-CVI confirms this assumption to be valid for cloud particles up to $25 \mu \mathrm{m}$ in diameter, which is the size region where most spherical particles reside (Mertes et al., 2007²).

A Forward Scattering Spectrometer Probe (FSSP-100; modified Model SPP100) was also employed, measuring the size distribution of cloud hydrometeors with diameters between 2 and $47 \mu \mathrm{m}$. Analysis of these data show that in mixed phase clouds, contamination from ice crystals is small. In any case, the response of the probe to ice is to produce a random distribution of sizes. Hence, the liquid spectrum is still clearly visible as it obeys a near lognormal spectral shape. Again, many potential problems with the inlet may be overcome by the ground-based operation of the probe.

Cloud liquid water content (LWC) was measured with a Particulate Volume Monitor (PVM-100, Gerber Scientific) at
1 min time resolution. The scattered light of a laser beam is related to LWC. The instrument response was calibrated typically every cloud-free day. When the zero-reading became higher than a certain threshold value (as recommended by the manufacturer) or when the detection unit was clogged with snow, the PVM was taken inside to defrost and the lens was cleaned. The response of the PVM to the presence of ice was quantified and empirically corrected by a combined analysis of the FSSP, PVM and CPI data (Verheggen et al., 2007³).

These measurements allow for the evaluation of the ice mass fraction (IMF) defined as IWC/(IWC+LWC corrected $_{\text {). In }}$ the following analysis, a 10-min time interval is classified as being "in-cloud" when the 15th percentile of the Cloud Water Content $\left(\mathrm{CWC}=\mathrm{IWC}+\mathrm{LWC}_{\text {corrected }}\right)$ is larger than $0.02 \mathrm{gm}^{-3}$ and the average $\mathrm{CWC}>0.05 \mathrm{gm}^{-3}$. This criterion is chosen to ascertain that measurements made in cloud edges, patchy clouds, and regions influenced by entrainment are excluded from the analysis as much as possible.

\section{Results and discussions}

\subsection{Comparison of $\mathrm{BC}$ measurements and characterization of the inlets}

The determination of the scavenged $\mathrm{BC}$ fraction required an assessment of artifacts induced by the sampling procedures at each inlet. Under clear sky conditions (period for which the average cloud water content (CWC) during 10 min was below $0.01 \mathrm{gm}^{-3}$ ), the validation of the quantitative sampling of submicrometer aerosol behind the two inlets and for the instruments used for $\mathrm{BC}$ mass concentration determination was done by using two MAAP instruments running downstream of the total and the interstitial inlets. Figure 1 shows the comparison of two identical instruments (MAAP/MAAP) behind the total and the interstitial inlets during cloud-free periods. It can be seen that the $\mathrm{BC}$ mass concentrations from the two MAAP's show good agreement $\left(r^{2}=0.97 ; \mathrm{BC}_{\mathrm{INT}}=0.95 \cdot \mathrm{BC}_{\mathrm{TOT}}+1.64 \mathrm{ngm}^{-3}\right)$. The $\mathrm{BC}$ concentrations of the interstitial inlet are slightly lower that those of the total inlet, which may be due to a slight under-pressure in the interstitial inlet caused by the $2-\mu \mathrm{m}$ cut of the cyclone, as mentioned in Sect. 2.4. Alternatively, the difference could be caused by the existence of some BC in coarse mode particles which were removed by the $2-\mu \mathrm{m}$ cut of the cyclone. In order to provide the best determination of the scavenged BC fraction, the interstitial MAAP data "in-cloud" were divided by a factor of 0.95 to correct for this deviation, since sampling artifacts were deemed the least likely in the total inlet.

\subsection{Concentrations of BC (in-cloud and out-of-cloud)}

Figure 2 shows an example of the evolution of the total and interstitial BC concentrations along with the evolution of the cloud liquid water content in the case of a liquid cloud. When 


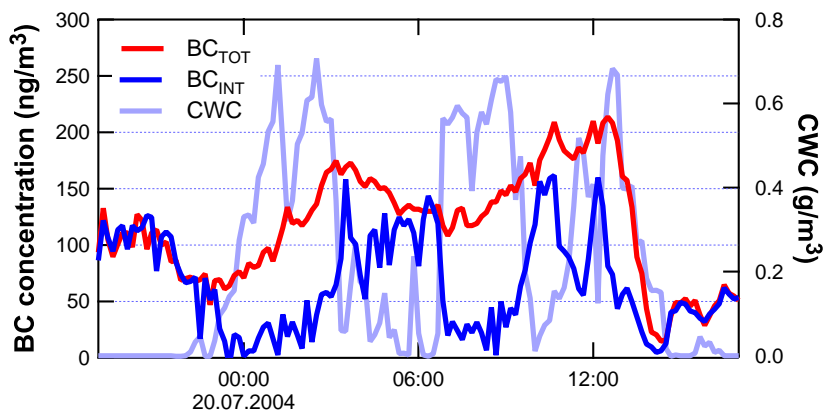

Fig. 2. Temporal evolution of the total and interstitial black carbon concentrations along with the temporal evolution of the cloud water content (CWC) for a liquid cloud (i.e., no ice phase).

clouds are absent $\mathrm{BC}$ concentrations behind the two inlets are similar. During cloud presence, BC scavenging is observed by a decrease in the $\mathrm{BC}$ concentration in the interstitial phase.

A mass closure was carried out under dry conditions by relating the $\mathrm{BC}$ concentration, the measured ionic chemical composition of the aerosol, its organic carbon fraction (determined with a Sunset OC/EC thermo-optical analyzer) and the submicrometer aerosol mass concentration (PM1, measured with a beta gauge, Thermo ESM Andersen FH62 I-R) on a time base of 24-h averages (Cozic et al., 2007b ${ }^{4}$ ). The average $\mathrm{BC}$ contribution to PM1 was found to be $2.5 \%$ in summer and $4.7 \%$ in winter.

Table 2 compares in-cloud and out-of-cloud BC concentrations measured behind the total and the interstitial inlets. As mentioned above, total and interstitial BC concentrations are very similar during out-of-cloud conditions. Higher concentrations are observed in summer than in winter for the out-of-cloud periods, which can be explained by the greater influence of boundary layer injections. During in-cloud periods the BC mass concentrations differ substantially between the total and the interstitial inlet: Here, the total $\mathrm{BC}$ concentrations are on average 1.2 and 1.8 times higher than the interstitial BC concentration for winter and summer, respectively. This is an indication that the fraction of $\mathrm{BC}$ containing particles in cloud droplets or ice crystals is significant (10.1 $\mathrm{ngm}^{-3}$ in winter and $22.3 \mathrm{ngm}^{-3}$ in summer). BC concentrations found at the Jungfraujoch (see Table 2) are similar to those found at other remote sites like the Arctic (3-174 $\left.\mathrm{ngm}^{-3}\right)$, Antarctic $\left(1.5-300 \mathrm{ngm}^{-3}\right)$ and marine environments $\left(0-500 \mathrm{ngm}^{-3}\right)$ (see Krivacsy et al., 2001, and references therein).

\subsection{Scavenged BC fraction}

The scavenged fraction of $\mathrm{BC}\left(F_{\mathrm{Scav}, \mathrm{BC}}\right)$ is defined as the fraction of $\mathrm{BC}$ that has been incorporated into cloud droplets or ice crystals. The mass concentration of black carbon in hydrometeors is approximated by the difference between the
Table 2. Average BC mass concentrations (total, interstitial) outof-cloud and in-cloud for winter and summer, as determined with the MAAP.

\begin{tabular}{lllll}
\hline$\left[\mathrm{ng} / \mathrm{m}^{3}\right]$ & \multicolumn{2}{c}{ Out-of-cloud } & \multicolumn{2}{c}{ In-cloud } \\
\hline & winter & summer & winter & summer \\
$\mathrm{BC}_{\text {Total }}$ & 54.2 & 64.9 & 81.4 & 50.3 \\
$\mathrm{BC}_{\text {Interstitial }}$ & 56.0 & 65.9 & 71.3 & 28.0 \\
\hline
\end{tabular}

concentrations downstream of the total and the interstitial inlets, and thus:

$F_{\text {Scav }, \mathrm{BC}}=\frac{\mathrm{BC}_{\text {cloud }}}{\mathrm{BC}_{\text {total }}}=\frac{\left(\mathrm{BC}_{\mathrm{TOT}}-\mathrm{BC}_{\mathrm{INT}}\right)}{\mathrm{BC}_{\mathrm{TOT}}}$

The scavenged aerosol volume fraction was calculated from the measured size distributions downstream of each inlet, analogous to the scavenged $\mathrm{BC}$ fraction. Comparing these two provides information on the role of $\mathrm{BC}$ in cloud droplet activation (this paper) and heterogeneous freezing (Cozic et al., $\left.2007 \mathrm{a}^{1}\right)$.

\subsection{The influence of environmental parameters on the scav-} enged $\mathrm{BC}$ fraction

A total of $1000 \mathrm{~h}$ of cloud periods were analyzed during winter 2004 (334 h), summer 2004 (373 h) and winter 2005 $(293 \mathrm{~h})$. This corresponds to an average cloud occurrence of $30 \%$, with a larger cloud presence in winter than in summer.

This large amount of data allows us to draw conclusions based on statistical analysis on the partitioning of black carbon between the cloud and interstitial phase and its dependency on environmental factors. In the following, statistical graphs are represented as box plots containing the different percentiles (10th, 25th, 50th, 75th, 90th \%) and an asterisk representing the mean average. All symbols are based on the same amount of data as given by $N$ (= number of 10-min averages per symbol).

The influence of the cloud liquid water content, $\mathrm{BC}$ mass concentration, temperature and cloud microphysics is analyzed in the next section. Several other factors were also considered, such as the wind direction, wind speed, time of the day, the wavelength used by an Aethalometer (AE31, MAGEE Scientific), but no clear influence on the scavenged $\mathrm{BC}$ fraction was observed for all these parameters.

In the following analysis, graphs are shown separately for two different temperature regimes $\left(T<-5^{\circ} \mathrm{C}\right.$ and $\left.T>-5^{\circ} \mathrm{C}\right)$ to distinguish between (potentially) mixed-phase and liquid clouds, respectively.

\subsubsection{Influence of the liquid water content (LWC)}

First, the relation between the scavenged $\mathrm{BC}$ fraction and liquid water content is presented for liquid clouds $\left(T>-5^{\circ} \mathrm{C}\right)$. 

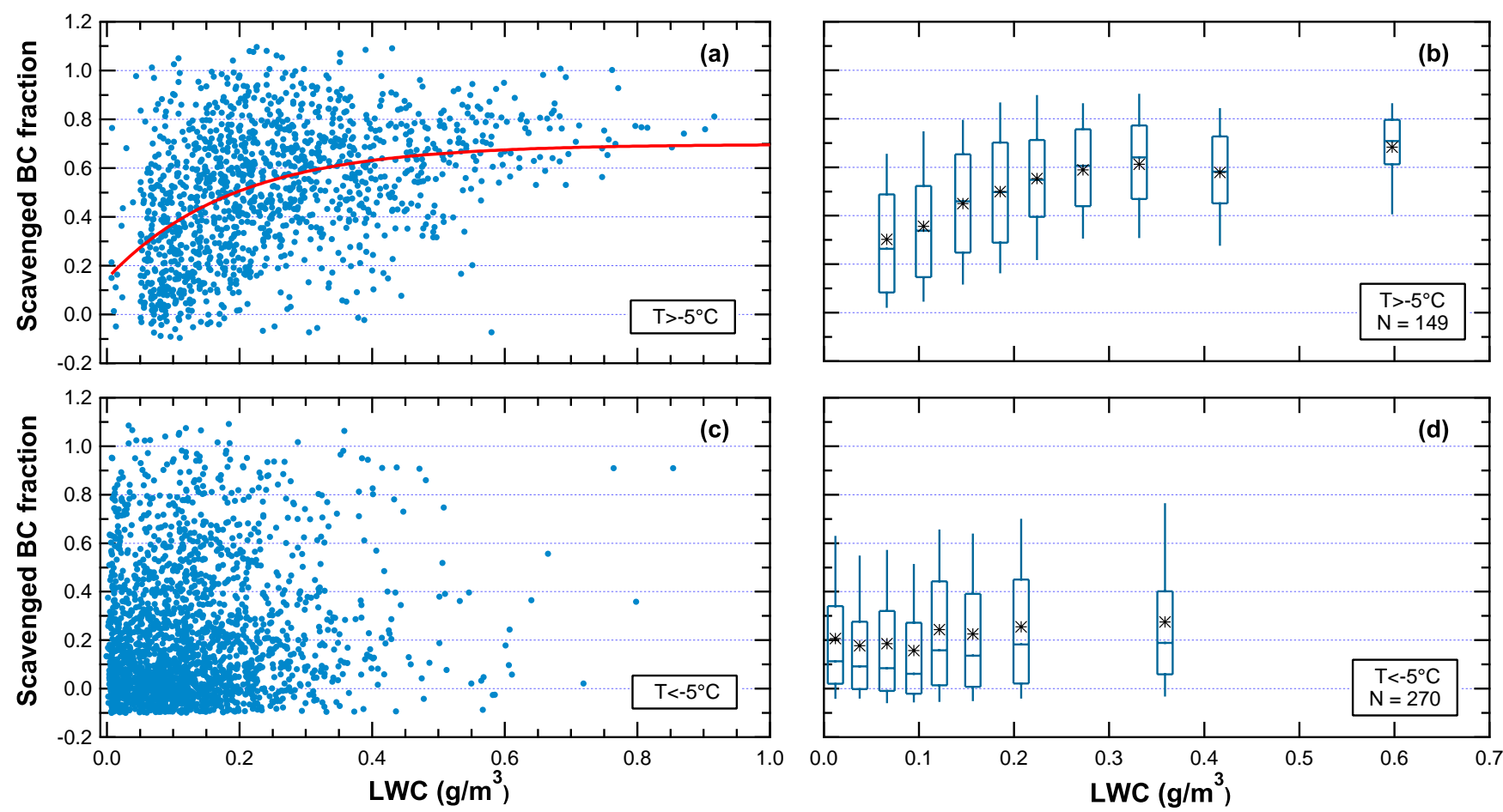

Fig. 3. Dependence of the scavenged $\mathrm{BC}$ fraction on the $\mathrm{LWC}$ at $\mathrm{T}>-5^{\circ} \mathrm{C}$ based on $224 \mathrm{~h}$ of in-cloud measurements and at $\mathrm{T}<-5^{\circ} \mathrm{C}(360 \mathrm{~h})$. Panel (a) and (c) show the raw data (10-min averages) from which the box plots of (b) and (d), respectively, were calculated. The box plots represent the different percentiles (10th, 25th, 50th, 75th, 90th \%) and the asterisk the mean. $N$ represents the number of 10-min data per box plot. The line in (a) shows an exponential fit to the 10-min data.

This temperature limit was chosen to ascertain that only liquid clouds were included, while keeping enough measurement data above this limit. Figure 3a shows the raw data (10min averages), exhibiting a large amount of scatter, because other factors than the one plotted on the $\mathrm{x}$-axis exert an influence on the partitioning as well. Figure $3 b$ shows the box plot version of the former, which shows the distributions of the data more clearly. Each asterisk represents the average of $N$ points of 10-min data; in this case each box plot represents the results of 149 points ( $\sim 25 \mathrm{~h}$ of measurements). The box plot around each asterisk represents the spread of the data in percentiles: $10 \%, 25 \%, 50 \%, 75 \%$ and $90 \%$. Thus, this does not correspond to an error, but is a measure of the variability in the data. This large variability impedes a more rigorous statistical analysis. In the following, only box plots will be shown and the appropriate fit equation of the 10-min data (as seen in Fig. 3a) and the 95\% confidence interval of the fit parameters will be given. This way of analysis will also be done for the other environmental parameters.

In Fig. 3b, it can be seen that for $T>-5^{\circ} \mathrm{C}$ $F_{\text {Scav, BC }}$ increases with increasing LWC as shown by fitting an exponential fit through the raw data, $F_{\text {Scav }, \mathrm{BC}}=(0.70 \pm 0.05)+(-0.55 \pm 0.06) \cdot \exp (-(5.29 \pm 1.7) \cdot \mathrm{LWC}$ $\left.\left[\mathrm{gm}^{-3}\right]\right)$. Figure $3 \mathrm{~d}$ shows that at lower temperature $(T<-$ $5^{\circ} \mathrm{C}$ ) this relationship is much less evident, indicating that here other factors influence the scavenged fraction more strongly than LWC does, as will be discussed below.

Figure $3 \mathrm{~b}$ also shows that the scavenged $\mathrm{BC}$ fraction increases with increasing LWC until reaching a plateau (of $60 \%)$ at high LWC $\left(>0.25 \mathrm{gm}^{-3}\right)$. At low LWC, activation of (BC containing) particles is limited by the availability of condensable water vapour.

The increase of the scavenged $\mathrm{BC}$ fraction with increasing LWC has also been observed at other mountain sites such as Mt. Sonnblick (Hitzenberger et al., 2000; Kasper-Giebl et al., 2000) and Rax (Hitzenberger et al., 2001), but not at Puy de Dôme (Sellegri et al., 2003). For both the Rax and Mt. Sonnblick an increase of the scavenged fraction up to a plateau of 0.8 for a $\mathrm{LWC}$ around $0.3 \mathrm{gm}^{-3}$ was observed. This is in accordance with the results obtained here where we find a plateau for $\mathrm{LWC}$ around $0.25 \mathrm{gm}^{-3}$.

\subsubsection{Influence of the total BC mass concentration}

Figure 4 shows a decrease of the scavenged fraction with increasing total $\mathrm{BC}$ concentration. BC mass concentrations are correlated with aerosol number concentrations, $N_{\text {tot }}$, of the Jungfraujoch aerosol. At high concentration, for temperatures above $-5^{\circ} \mathrm{C}$ (a), corresponding to summer data only, a larger number of available CCN may deplete the available water vapour more rapidly and decrease the 

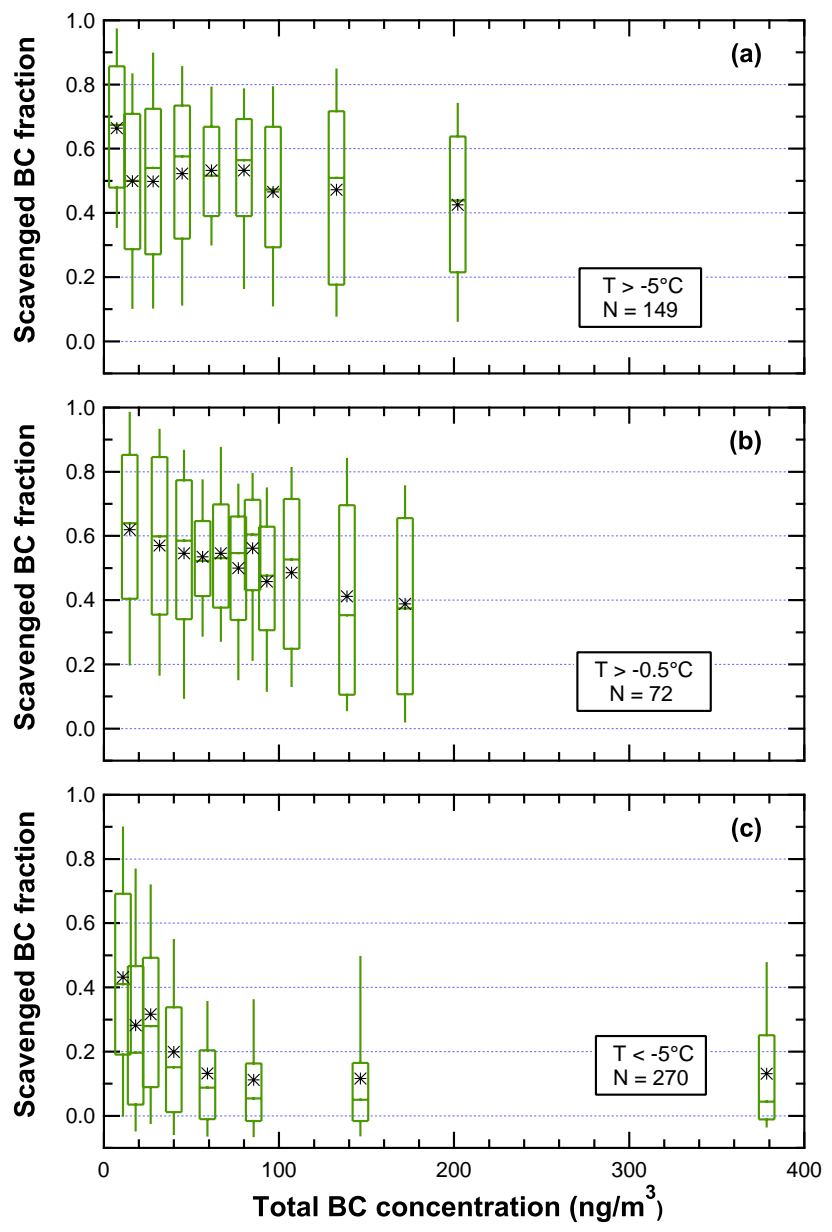

Fig. 4. Dependence of the scavenged $\mathrm{BC}$ fraction on the $\mathrm{BC}$ concentration measured downstream of the total inlet at $\mathrm{T}>-5^{\circ} \mathrm{C}$ based on $224 \mathrm{~h}$ of in-cloud measurements $(\mathbf{a})$, at $\mathrm{T}>-0.5^{\circ} \mathrm{C}(\mathbf{b}, 132 \mathrm{~h})$ and at $\mathrm{T}<-5^{\circ} \mathrm{C}(\mathbf{c}, 360 \mathrm{~h})$.

super-saturation to below critical levels. As a result, the relative increase of the number of activated particles is smaller than that of the total number of particles, resulting in a lower scavenged fraction. A linear fit through the data gives $F_{\mathrm{Scav}, \mathrm{BC}}=(-0.00064 \pm 0.00023) \cdot \mathrm{BC}_{\mathrm{TOT}}$ $\left[\mathrm{ngm}^{-3}\right]+(0.56 \pm 0.02)$; the decreasing trend of $F_{\text {Scav, BC }}$ is even much more pronounced for temperatures above $-0.5^{\circ} \mathrm{C}$ (Fig. 4b), for which the best linear fit is $F_{\mathrm{Scav}, \mathrm{BC}}=(-0.0014 \pm 0.0004) \cdot \mathrm{BC}_{\mathrm{TOT}}$ $\left[\mathrm{ngm}^{-3}\right]+(0.63 \pm 0.04)$.

For $T<-5^{\circ} \mathrm{C}$ (c), the presence of ice particles in the cloud keeps $F_{\text {Scav, BC }}$ low except when $\mathrm{BC}_{\text {TOT }}$ (and thus $N_{\text {TOT }}$ ) is extremely low. In such clean conditions, the maximum supersaturation was probably higher than in more polluted cases, allowing a larger fraction of aerosol particles to be activated, which results in a higher value of $F_{\mathrm{Scav}, \mathrm{BC}}$. The exponential equation fit shows a significant decrease $\left(F_{\text {Scav }, \mathrm{BC}}=(0.12 \pm 0.02)+(0.58 \pm 0.09) \cdot \exp (-(0.06 \pm 0.01)\right.$

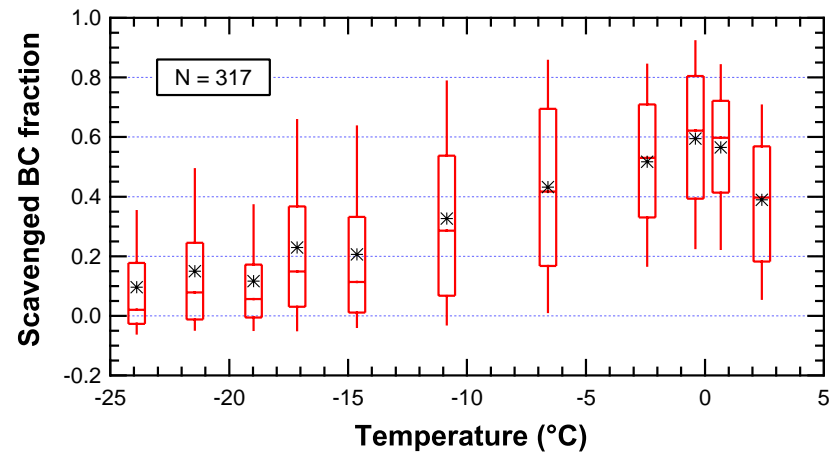

Fig. 5. Dependence of the scavenged BC fraction on temperature based on $581 \mathrm{~h}$ of in-cloud measurements.

$\left.\left.\left.\cdot \mathrm{BC}_{\text {TOT }}\left[\mathrm{ngm}^{-3}\right]\right)\right)\right)$, i.e. the scavenged fraction is significantly smaller at high $\mathrm{BC}$ concentrations than it is at low BC concentrations.

In previous studies, the influence of the total BC concentration was investigated with sometimes different results. In the Po valley (Hallberg et al., 1992), at Kleiner Feldberg (Hallberg et al., 1994) and at Great Dun Fell (Gieray et al., 1997) a decrease of the scavenged fraction with increasing BC mass concentration was observed, as in the present study. In contrast, no dependence was found at Mt. Sonnblick (Hitzenberger et al., 2000; Kasper-Giebl et al., 2000) and Rax (Hitzenberger et al., 2001).

\subsubsection{Influence of temperature}

The main interest of this study relates to the influence of the coexisting ice and liquid phases on the scavenged $\mathrm{BC}$ fraction. The influence of the ambient temperature is one of the parameters showing this effect (Fig. 5). The scavenged BC fraction decreases with decreasing temperature, from $60 \%$ in liquid clouds in summer (at $T=0^{\circ} \mathrm{C}$ ) down to $\sim 10 \%$ in mixed phase clouds in winter. Data with $T<0^{\circ} \mathrm{C}$ is best parameterized with $\left(F_{\mathrm{Scav}, \mathrm{BC}}=(0.03 \pm 0.111)+(0.66 \pm 0.35) /(1+\exp (-\right.$ $\left.\left.\left(T\left[{ }^{\circ} \mathrm{C}\right]-(9.32 \pm 4.17)\right) /(6.77 \pm 4.40)\right)\right)$. This observed trend is consistent with the Wegener-Bergeron-Findeisen (WBF) process: In a mixed-phase cloud there is a flux of water vapour from the liquid phase to the ice phase due to the lower saturation vapour pressure over ice than over liquid water. This leads to the evaporation of liquid droplets, thus releasing the aerosol material back into the interstitial phase. This in turn results in a decreased scavenged fraction, since ice nuclei (IN) (and thus ice crystals) are much less numerous than $\mathrm{CCN}$. So, many cloud droplets are evaporated to the benefit of the formation and growth of a few ice crystals.

The previous scenario is valid when the mixed phase clouds we observed started off as liquid clouds, after which ice nucleation took place by heterogeneous freezing of droplets. If, however, ice crystals were formed before all available $\mathrm{CCN}$ had a chance to activate, the formation of 


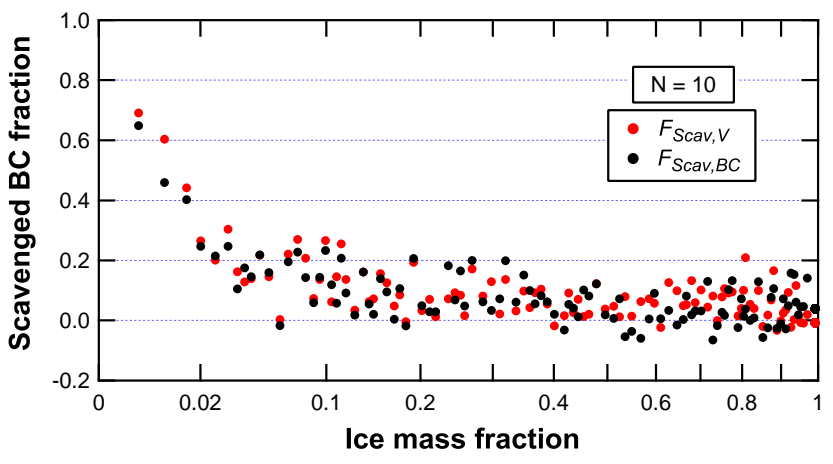

Fig. 6. Dependence of the scavenged BC fraction (black dots) and the scavenged bulk volume fraction (red dots) on the ice mass fraction, based on $176 \mathrm{~h}$ of wintertime measurements. Each symbol denotes the average of $N$ points of 10-min data. $\mathrm{X}$-axis is given on a quadratic scale for clarity.

those ice crystals could prevent further $\mathrm{CCN}$ from activating by quickly lowering the supersaturation. This is based on the same physical mechanism as the WBF process (i.e. difference in vapour pressure), except that drops are prevented from activating instead of being evaporated. The result is the same: a lower activated fraction at lower temperatures, because there is more chance for ice crystals to be present.

At higher temperatures, $T>0^{\circ} \mathrm{C}$, a reverse trend is observed (Fig. 5). The lowest values of the scavenged fraction can be explained by the fact that very high aerosol number concentrations $\left(N_{\mathrm{TOT}}>500 \mathrm{~cm}^{-3}\right)$ coincide with higher temperatures, which leads to a limitation of water vapour available to activate more ambient particles, as shown for the $\mathrm{BC}$ mass concentration in Fig. 4b.

The highest average scavenged fraction (around 60\%), which corresponds to a liquid cloud, not influenced by high aerosol concentrations, is quite high and is explained by the existence of internally mixed aerosol particles as shown in Table 1 above. Nevertheless a comparison of the scavenged fraction found at the Jungfraujoch with other studies is difficult since no information on the average temperature is given in the other studies.

Summarizing, the influence of LWC and total BC concentration on the scavenged $\mathrm{BC}$ fraction is strongest for low LWC and low BC concentration (see Figs. 3 and 4). The observed increase in $F_{\text {Scav, BC }}$ with increasing temperature is consistent with the Wegener-Bergeron-Findeisen process.

\subsubsection{Influence of ice mass fraction}

The scavenged $\mathrm{BC}$ fraction dependence on temperature was explained by the presence of ice crystals. Therefore, an analysis of the influence of the cloud ice mass fraction is presented here. The scavenged BC fraction decreases with increasing ice mass fraction (Fig. 6), as expected from the Wegener-Bergeron-Findeisen process. The exponential fit

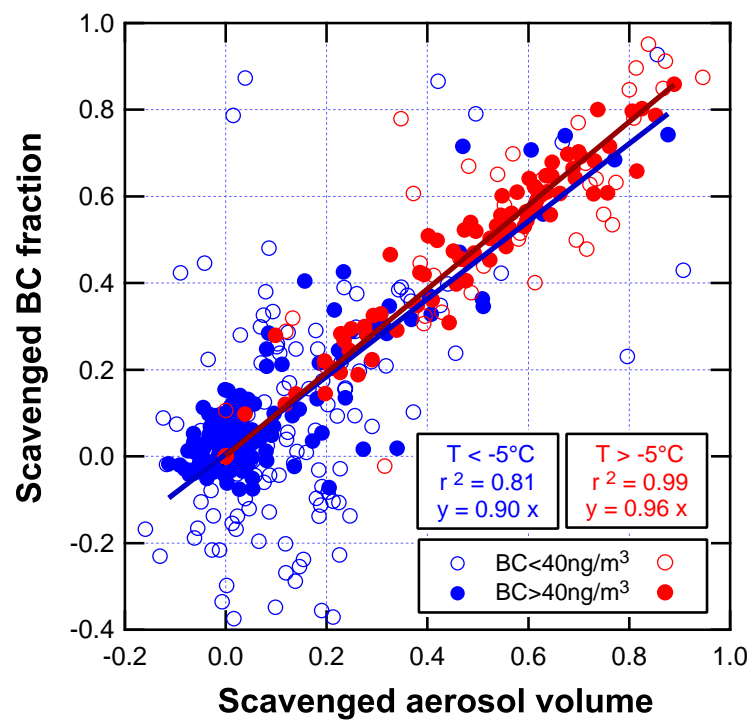

Fig. 7. Correlation between the scavenged $\mathrm{BC}$ fraction and the scavenged bulk volume fraction for $\mathrm{T}<-5^{\circ} \mathrm{C}$ (blue dots) and $\mathrm{T}>-5^{\circ} \mathrm{C}$ (red dots). Data with low concentrations (open circles; BC concentrations $<40 \mu \mathrm{g} / \mathrm{m}^{3}$ ) were excluded from the correlation analysis.

equation with $95 \%$ confidence interval errors is given by

$$
\begin{aligned}
F_{\text {Scav }, \mathrm{BC}}= & (0.05 \pm 0.02)+(0.92 \pm 0.25) \\
& \exp (-(8.95 \pm 2.17) \sqrt{\mathrm{IMF}})
\end{aligned}
$$

In parallel to this study, the scavenged fractions of the bulk aerosol volume and number were investigated (Verheggen et al., $2007^{3}$ ). The scavenged volume fraction was derived from measured number size distributions assuming spherical particles and is defined as the ratio of particle volume scavenged into cloud droplets or ice crystals (obtained from total minus interstitial) to the total volume of particles, analogous to the scavenged BC fraction. Figure 6 presents the scavenged aerosol volume fraction as a function of the ice mass fraction (red dots). The exponential fit equation is given by

$$
\begin{aligned}
F_{\text {Scav }, \mathrm{V}=} & (0.06 \pm 0.01)+(1.07 \pm 0.25) \\
& \exp (-(9.33 \pm 1.90) \sqrt{\mathrm{IMF}})
\end{aligned}
$$

The dependence of the scavenged aerosol volume and number fraction on temperature, total particle number, LWC and ice mass fraction shows similar trends as described here for BC (Verheggen et al., 2007³).

\subsubsection{Relation between $\mathrm{BC}$ and bulk aerosol scavenging}

Figure 7 shows the correlation between the scavenged BC fraction and the scavenged volume fraction separately for $T<-5^{\circ} \mathrm{C}$ and $T>-5^{\circ} \mathrm{C}$. The very high correlation for higher temperatures $\left(r^{2}=0.99 ; F_{\mathrm{Scav}, \mathrm{BC}}=0.96 \cdot F_{\mathrm{Scav}, \mathrm{V}}\right)$ indicates that in liquid clouds BC behaves like the bulk aerosol. This is due to aged $\mathrm{BC}$ which exhibits a greater hygroscopicity and 
therefore enhances the transfer of $\mathrm{BC}$ into cloud droplets via nucleation scavenging. At low temperatures, the correlation between the two scavenged fractions is slightly lower $\left(r^{2}=0.81 ; F_{\mathrm{Scav}, \mathrm{BC}}=0.90 \cdot F_{\mathrm{Scav}, \mathrm{V}}\right)$. It has to be noted that for these values low concentrations below $40 \mathrm{ngm}^{-3}$ (open circles) were not considered because they were generating a lot of scatter without changing the slope of the correlation. Including all points, the correlation was still quite high but with a lot more of scatter at low temperatures $\left(r^{2}=0.245\right.$; $\left.F_{\mathrm{Scav}, \mathrm{BC}}=0.86 \cdot F_{\mathrm{Scav}, \mathrm{V}}\right)$ and no real difference at high temperatures $\left(r^{2}=0.95 ; F_{\mathrm{Scav}, \mathrm{BC}}=0.95 \cdot F_{\mathrm{Scav}, \mathrm{V}}\right)$.

\section{Summary}

The influence of environmental parameters on the scavenged $\mathrm{BC}$ fraction in liquid and mixed phase clouds was studied. The measurements showed that the scavenged $\mathrm{BC}$ fraction increases with increasing liquid water content for values of LWC up to $0.25 \mathrm{gm}^{-3}$, and decreases with increasing $\mathrm{BC}$ concentration for a total $\mathrm{BC}$ concentration up to $35 \mathrm{ngm}^{-3}$. It was found that for a large temperature range (between $-25^{\circ} \mathrm{C}$ and $0^{\circ} \mathrm{C}$ ) the scavenged $\mathrm{BC}$ fraction increases with increasing temperature, up to $60 \%$ in summer. This decrease of the scavenged $\mathrm{BC}$ fraction with decreasing temperature can be explained by the evaporation of liquid droplets in the presence of ice crystals (Wegener-Bergeron-Findeisen process). This was confirmed by the demonstrated influence of the ice mass fraction on the scavenged $\mathrm{BC}$ fraction. The scavenged $\mathrm{BC}$ fraction showed similar dependences on temperature, total particle number, LWC, and ice mass fraction, as the dependence of the scavenged aerosol volume and number fraction on the same parameters (Verheggen et al., $2007^{3}$ ). BC was found to be scavenged into the cloud phase to the same extent as the bulk aerosol due to aged BC exhibiting a larger hygroscopicity, which enhances the transfer of $\mathrm{BC}$ into cloud droplets via nucleation scavenging.

Acknowledgements. We thank the International Foundation High Altitude Research Stations Jungfraujoch and Gornergrat (HFSJG) for the opportunity to perform experiments at the Jungfraujoch. This work was supported by MeteoSwiss (GAW program), as well as the German Science foundation (grants $\mathrm{He}$ 939/8-1 and $\mathrm{He}$ 939/17-1) and the EC project ACCENT.

Edited by: U. Lohmann

\section{References}

Albrecht, B. A.: Aerosols, cloud microphysics, and fractional cloudiness, Science, 245, 1227-1230, 1989.

Alfaro, S. C., Lafon, S., Rajot, J. L., Formenti, P., Gaudichet, A., and Maille, M.: Iron oxides and light absorption by pure desert dust: An experimental study, J. Geophys. Res., 109(D8), doi:10.1029/2003JD004374, 2004.
Baltensperger, U., Gäggeler, H. W., Jost, D. T., Lugauer, M., Schwikowski, M., Weingartner, E., and Seibert, P.: Aerosol climatology at the high-alpine site Jungfraujoch, Switzerland, J. Geophys. Res., 102, 19707-19715, 1997.

Bond, T. C., Anderson, T. L., and Campbell, D.: Calibration and intercomparison of filter-based measurements of visible light absorption by aerosols, Aerosol Sci. Technol., 30, 582-600, 1999.

Chylek, P., Lesins, G. B., Videen, G., Wong, J. G. D., Pinnick, R. G., Ngo, D., and Klett, J. D.: Black carbon and absorption of solar radiation by clouds, J. Geophys. Res., 101, 23 365-23 371, 1996.

Collaud Coen, M. C., Weingartner, E., Schaub, D., Hueglin, C., Corrigan, C., Henning, S., Schwikowski, M., and Baltensperger, U.: Saharan dust events at the Jungfraujoch: detection by wavelength dependence of the single scattering albedo and first climatology analysis, Atmos. Chem. Phys., 4, 2465-2480, 2004, http://www.atmos-chem-phys.net/4/2465/2004/.

Collaud Coen, M. C., Weingartner, E., Nyeki, S., Cozic, J., Henning, S., Verheggen, B., Gehrig, R., and Baltensperger, U.: Long-term trend analysis of aerosol variables at the high alpine site Jungfraujoch, J. Geophys. Res., doi:10.1029/2006JD007995, 2007.

Connolly, P.: An investigation into the microphysics of deep convection, PhD Thesis, University of Manchester, 2006.

Connolly, P. J., Flynn, M. J., Ulanowski, Z., Choularton, T. W., and Gallagher, M. W.: Calibration of 2-D imaging probes using calibration beads and ice crystal analogues. Part 1: The depth-offield, J. Atmos. Oceanic Technol., in press, 2007.

Gieray, R., Wieser, P., Engelhardt, T., Swietlicki, E., Hansson, H. C., Mentes, B., Orsini, D., Martinsson, B., Svenningsson, B., Noone, K. J., and Heintzenberg, J.: Phase partitioning of aerosol constituents in cloud based on single-particle and bulk analysis, Atmos. Environ., 31, 2491-2502, 1997.

Hallberg, A., Ogren, J. A., Noone, K. J., Heintzenberg, J., Berner, A., Solly, I., Kruisz, C., Reischl, G., Fuzzi, S., Facchini, M. C., Hansson, H. C., Wiedensohler, A., and Svenningsson, I. B.: Phase partitioning for different aerosol species in fog, Tellus B, 44, 545-555, 1992.

Hallberg, A., Noone, K. J., Ogren, J. A., Svenningsson, I. B., Flossmann, A., Wiedensohler, A., Hansson, H. C., Heintzenberg, J., Anderson, T. L., Arends, B. G., and Maser, R.: Phase partitioning of aerosol-particles in clouds at Kleiner-Feldberg, J. Atmos. Chem., 19, 107-127, 1994.

Hansen, A. D. A., Rosen, H., and Novakov, T.: The aethalometer - an instrument for the real-time measurement of optical absorption by aerosol particles, Sci. Total Environ., 36, 191-196, 1984.

Haywood, J. and Boucher, O.: Estimates of the direct and indirect radiative forcing due to tropospheric aerosols: A review, Rev. Geophys., 38, 513-543, 2000.

Heintzenberg, J. and Leck, C.: Seasonal-variation of the atmospheric aerosol near the top of the marine boundary-layer over Spitsbergen related to the Arctic sulfur cycle, Tellus B, 46, 5267, 1994.

Henne, S., Furger, M., and Prevot, A. S. H.: Climatology of mountain venting-induced elevated moisture layers in the lee of the Alps, J. Appl. Meteorol., 44(5), 620-633, 2005.

Henning, S., Weingartner, E., Schmidt, S., Wendisch, M., Gäggeler, H. W., and Baltensperger, U.: Size-dependent aerosol activation at the high-alpine site Jungfraujoch (3580 m asl), Tellus B, 54, 
82-95, 2002.

Henning, S., Bojinski, S., Diehl, K., Ghan, S., Nyeki, S., Weingartner, E., Wurzler, S., and Baltensperger, U.: Aerosol partitioning in natural mixed-phase clouds, Geophys. Res. Lett., 31, L06101, doi:10.1029/2003GL019025, 2004.

Heymsfield, A. J., Bansemer, A., Schmitt, C., Twohy, C., and Poellot, M. R.: Effective ice particle densities derived from aircraft data, J. Atmos. Sci., 61, 982-1003, 2004.

Hitzenberger, R., Berner, A., Kromp, R., Kasper-Giebl, A., Limbeck, A., Tscherwenka, W., and Puxbaum, H.: Black carbon and other species at a high-elevation European site (Mount Sonnblick, $3106 \mathrm{~m}$, Austria): Concentrations and scavenging efficiencies, J. Geophys. Res., 105, 24 637-24 645, 2000.

Hitzenberger, R., Berner, A., Giebl, H., Drobesch, K., KasperGiebl, A., Loeflund, M., Urban, H., and Puxbaum, H.: Black carbon (BC) in alpine aerosols and cloud water - concentrations and scavenging efficiencies, Atmos. Environ., 35, 5135-5141, 2001.

Hoffer, A., Gelencsér, A., Guyon, P., Kiss, G., Schmid, O., Frank, G., Artaxo, P., and Andreae, M. O.: Optical properties of humiclike substances (HULIS) in biomass-burning aerosols, Atmos. Chem. Phys., 6, 3563-3570, 2006, http://www.atmos-chem-phys.net/6/3563/2006/.

Intergovernmental Panel on Climate Change (IPCC) (2001): Climate Change 2001: The Scientific Basis, Cambridge Univ. Press, New York, 2001.

Kasper-Giebl, A., Koch, A., Hitzenberger, R., and Puxbaum, H.: Scavenging efficiency of 'aerosol carbon' and sulfate in supercooled clouds at Mt. Sonnblick (3106 m a.s.l., Austria), J. Atmos. Chem., 35, 33-46, 2000.

Krivacsy, Z., Hoffer, A., Sarvari, Z., Temesi, D., Baltensperger, U., Nyeki, S., Weingartner, E., Kleefeld, S., and Jennings, S. G.: Role of organic and black carbon in the chemical composition of atmospheric aerosol at European background sites, Atmos. Environ., 35, 6231-6244, 2001

Lau, K. M. and $\mathrm{Wu}, \mathrm{H}$. T.: Warm rain processes over tropical oceans and climate implications, Geophys. Res. Lett., 30, 2290, doi:10.1029/2003GL018567, 2003.

Linke, C., Möhler, O., Veres, A., Mohacsi, A., Bozoki, Z., Szabo, G., and Schnaiter, M.: Optical properties and mineralogical composition of different Saharan mineral dust samples: a laboratory study, Atmos. Chem. Phys., 6, 3315-3323, 2006,

http://www.atmos-chem-phys.net/6/3315/2006/.
Lohmann, U.: A glaciation indirect aerosol effect caused by soot aerosols, Geophys. Res. Lett., 29(4), 1052, doi:10.1029/2001GL014357, 2002.

Lohmann, U. and Feichter, J.: Global indirect aerosol effects: a review, Atmos. Chem. Phys., 5, 715-737, 2005, http://www.atmos-chem-phys.net/5/715/2005/.

Lohmann, U. and Diehl, K.: Sensitivity studies of the importance of dust ice nuclei for the indirect aerosol effect on stratiform mixedphase clouds, J. Atmos. Sci., 63, 968-982, 2006.

Mitchell, D. L.: Use of mass- and area-dimensional power laws for determining precipitation particle terminal velocities, J. Atmos. Sci., 53, 1710-1723, 1996.

Petzold, A. and Schönlinner, M.: Multi-angle absorption photometry - a new method for the measurement of aerosol light absorption and atmospheric black carbon, J. Aerosol Sci., 35, 421-441, 2004.

Reid, J. S., Hobbs, P. V., Liousse, C., Martins, J. V., Weiss, R. E., and Eck, T. F.: Comparisons of techniques for measuring shortwave absorption and black carbon content of aerosols from biomass burning in Brazil, J. Geophys. Res., 103, 32 031-32 040, 1998.

Rogers, R. R. and Yau, M. K.: A Short Course in Cloud Physics, Pergamon, Tarrytown, N.Y, 1989.

Sellegri, K., Laj, P., Dupuy, R., Legrand, M., Preunkert, S., and Putaud, J. P.: Size-dependent scavenging efficiencies of multicomponent atmospheric aerosols in clouds, J. Geophys. Res., 108, 4334, doi:10.1029/2002JD002749, 2003.

Twomey, S.: The influence of pollution on the shortwave albedo of clouds, J. Atmos. Sci., 34, 1149-1152, 1977.

Weingartner, E., Burtscher, H., and Baltensperger, U.: Hygroscopic properties of carbon and diesel soot particles, Atmos. Environ., 31, 2311-2327, 1997.

Weingartner, E., Nyeki, S., and Baltensperger, U.: Seasonal and diurnal variation of aerosol size distributions $(10<\mathrm{D}<750 \mathrm{~nm})$ at a high-alpine site (Jungfraujoch $3580 \mathrm{~m}$ asl), J. Geophys. Res., 104, 26 809-26 820, 1999.

Weingartner, E., Saathoff, H., Schnaiter, M., Streit, N., Bitnar, B., and Baltensperger, U.: Absorption of light by soot particles: determination of the absorption coefficient by means of aethalometers, J. Aerosol Sci., 34, 1445-1463, 2003. 